\title{
MINI OPCAB Mammary to LAD and Optimal Medical Treatment in High Risk Patients with Multivessel Coronary Disease Long Term Results
}

\author{
Natalia Scialacomo and Federico J Benetti* \\ Cardiac Surgeon, Benetti Foundation \\ ${ }^{\star}$ Corresponding author: Federico Benetti, Cardiac Surgeon, Benetti Foundation, Alem 1846 Rosario Zip 2000 Argentina; E-mail: federicobenetti@hotmail.com \\ Received: June 03, 2021; Accepted: June 10, 2021; Published: July 15, 2021

\begin{abstract}
Old patients with multivessel coronary artery disease (CAD) are a challenging group to treat The MINI OPCAB technique is an operation were we connected the left internal mammary to LAD artery through an small incision in the lower part of the sternum. The objective of this prospective study was to show the results and survival during a follow-up in a group of high-risk patients with Multivessel disease treated with the MINI OPCAB operation Results The operative mortality was $0 \%$ in this group of patients. The incidence of perioperative infarction was $0 \%$. The average time of the operation was 2 hours and 20 minutes MACE in this group of patients at 80 months was $0 \%$. The survival rate (K-M) at 80 months was $82 \%$ Conclusion We strong believe the combination of a MINI OPCAB operation in high risk patients with multivessel coronary disease and optimal medical treatment an eventually and stent in a very big dominate artery is a valuable option for this type of patients more experience is needed to confirm this data.
\end{abstract}

Statistics: Data were analysed with the Statistical Package for Social Sciences (SPSS, Version 15.0).

Keywords: Coronary surgery and medical treatment, Coronary surgery plus medical treatment, MINI OPCAB in High risk patients, Treatment in high risk coronary patients, Treatment in multivessel coronary

\section{Introduction}

Old patients with multivessel coronary artery disease (CAD) are a challenging group to treat; these cases elicit discussion within heart teams regarding the actual benefit of undertaking major surgery on these patients and often lead to abandon the surgical option. Since these patients usually present with age-related comorbidities, preoperative risk stratification is mandatory and less invasive treatment options are favorable. Although conventional surgical revascularization can be carried out in old patients with acceptable short- and long-term a result, perioperative mortality is markedly elevated [1]. For high-riskpatients with multivessel CAD, not eligible to on-pump complete revascularization surgery or percutaneous procedures, incomplete revascularization with OPCAB LIMA-onLAD offers benefits in survival when compared to OMT (Optimal medical treatment) alone [2]. MIDCAB is an effective approach for managing high-risk patients with symptomatic three-vessel coronary artery disease. Longer follow-up is needed to further clarify patient selection and the long-term outcome of this approach $[3,4]$.

The MINI OPCAB techniqueis an operation were we connected the left internal mammary to LAD artery through an small incision in the lower part of the sternum [5] The long term results were previous described [6]. The objective of this prospective study was to show the results and survival during a follow-up in a group of high-risk patients with Multivessel disease treated with the MINI
OPCAB operation and maximal medical treatment during the last 7 years in our Foundation.

\section{Patients and Methods}

During the last ten years 14 high risk patients with multivessel coronary disease prospective enroled received a MINI OPCAB operation Left mammary to the LAD bypass plus maximal medical treatment and strictly risk factor controls. The average age was 71, 07(st D 9,051 ci 95\%), 21\% were females: The preoperative Logistic Euroscore was 10, 68 (st D 5,407 CI 95\%). The patients were strictly follow monthly in the Clinic of the Foundation by the Heart Team.

\section{Results}

The operative mortality was $0 \%$ in this group of patients. The incidence of perioperative infarction was $0 \%$. The average time of the operation was 2 hours and 20 minutes. Ten (71\%) of the patients were extubated in the operating room. The average time of Hospitalization was two days and eleven hours One patient at 30 days received a PTCA STENT in the Right Coronary artery; was a very big and dominant artery and the patient started again with angor after the procedure;another patient with a big dominant Circumflex was stenting inmediatly after the operation MACE in this group of patients at 80 months was $0 \%$. We lost one patient at 85 years old due to a cerebrovascular accident at almost 5 years (62 months). The survival rate $(\mathrm{K}-\mathrm{M})$ at 80 months was $82 \%$ 


\section{Discussion}

The primarily supposed benefit of off-pump surgery in elderly patients is still undetermined [7] in selected patients with multivessel disease (MVD), MIDCAB can be reasonable with concomitant percutaneous coronary intervention (PCI) as a hybrid procedure $[8,9]$. To date, the 2014 ESC/EACTS guidelines on myocardial revascularization judge hybrid revascularization as reasonable only in selected patients when PCI of the LAD is not an option and conventional CABG is associated with an increased surgical risk [10].

During a total of 6.3 (median, 4.9) years of follow-up, the primary composite outcome of all-cause mortality, myocardial infarction, stroke, or repeat revascularization occurred in 26\% (141/550) and 34\% (179/529) of patients in the CABG and PCI groups, respectively (hazard ratio (HR), 0.75; 95\% confidence interval (CI), 0.60-0.94; $\mathrm{P}=.012$ ). CABG was associated with fewer myocardial infarction ( $4 \%$ vs. $8 \%$ for PCI; HR, 0.48; 95\% CI, 0.29-0.80; $\mathrm{P}=.037)$; and repeat revascularizations (8\% vs. 17\% for PCI; HR, 044; 95\% CI, 0.31-0.64; P <.001), but had little association with all-cause mortality or stroke [11].

For high-risk patients with multivessel CAD, not eligible to onpump complete revascularization surgery or percutaneous procedures, incomplete revascularization with OPCAB LIMA-on-LAD offers benefits in survival when compared to OMT alone.

Patients who underwent OPCAB survived more than those discharged in optimal medical treatment [2]. Considerably more data are available concerning the outcome of old patients undergoing CABG. Sen et al. compared the outcome of 240 octogenarians with matched younger patients in a retrospective two-centre analysis. They found a statistically significant higher 30-day mortality rate of $6.8 \%$ in the elderly patients. Age was identified as a risk factor for early death [12] Gunn et al. [13] reported a 30-day mortality rate of $8.8 \%$ in octogenarians after CABG in a retrospective analysis where perioperative strokes were significantly more frequent than in younger patients (5.5 vs. 1.6\%). We strong believe the combination of a MINI OPCAB operation in high risk patients with multivessel coronary disease and optimal medical treatment an eventually and stent in a very big dominate artery is a valuable option for this type of patients more experience is needed to confirm this data.

\section{References}

1. Grischa Hoffmann. Christine Friedrich, Moritz Barrabas, Rainer Petzina, Assad Haneya, et al. (2016) Short- and long-term follow-up after minimally invasive direct coronary artery bypass. Interact Cardio Vasc Thorac Surg 23: 377-382. [crossref]

2. Prestipino F, Cristiano Spadaccio, Antonio Nenna, Fraser Wh Sutherland, Gwyn W Beattie, et al. (2016) Off-pump coronary artery bypass grafting versus optimal medical therapy alone: effectiveness of incomplete revascularization in high risk patients. J Geriatr Cardiol 13: 23-30. [crossref]

3. Benetti Method for coronary artery bypass (1999) United States Patent N 5,888.

4. Izzat MB, Yim AP (1997) Minimally invasive LAD revascularization in high-risk patients with three-vessel coronary artery disease. Int J Cardiol 1: S101-4. [crossref]

5. Federico j Benetti, Natalia Scialacomo ,Gustavo Mazzolino (2021) Mini Opcab Operation Surgical Thecnique. Surg Thecnol Int 38: sti38/1400. [crossref]

6. Federico J Benetti (2010) MINI-off-pump coronary artery bypass graft: long-term results. Future Cardiology 6: 791-795. [crossref]

7. Deppe AC, Oliver J Liakopoulos, Elmar W Kuhn, Ingo Slottosch, Maximilian Scherner, et al. (2015) Minimally invasive direct coronary bypass grafting versus percutaneous coronary intervention for single-vessel disease: a meta-analysis of 2885 patients. Eur J Cardiothoracic Surg 47: 397-406. [crossref]

8. Holzhey, Stephan Jacobs, Michael Mochalski, Denis Merk, Thomas Walther, et al. (2008) Minimally invasive hybrid coronary artery revascularization. Ann Thorac Surg 86: $1856-60$. [crossref]

9. Repossini A, Maurizio Tespili, Antonio Saino, Igor Kotelnikov, Annalisa Moggi, et al. (2013) Hybrid revascularization in multivessel coronary artery disease. Eur J Cardiothorac Surg 44: 288-93. [crossref]

10. Kolh P, Fernando Alfonso, Jean-Philippe Collet, Jochen Cremer, Volkmar Falk, et al (2014) 2014 ESC/EACTS Guidelines on myocardial revascularization: the Task Force on Myocardial Revascularization of the European Society of Cardiology (ESC) and the European Association for Cardio-Thoracic Surgery (EACTS). Eur J Cardiothorac Surg 46: 517-92. [crossref]

11. Chang, Cheol Whan Lee, Jung-Min Ahn, Rafael Cavalcante, Yohei Sotomi, et al. (2016) Outcomes of Coronary Artery Bypass Graft Surgery Versus Drug-Eluting Stents in Older Adults. Ann Thorac Surg 103: 517-525. [crossref]

12. Sen B, Bernd Niemann, Peter Roth, Raed Aser, Markus Schönburg, et al. (2012) Short- and long-term outcomes in octogenarians after coronary artery bypass surgery. Eur J Cardiothorac Surg 42: e102-7. [crossref]

13. Gunn j, Kari Kuttila, Francesco Vasques, Raine Virtanen, Anne Lahti, et al. (2012) Comparison of results of coronary artery bypass grafting versus percutaneous coronary intervention in octogenarians. Am J Cardiol 110: 1125-1129. [crossref]

\section{Citation:}

Scialacomo N, Benetti FJ (2021) MINI OPCAB Mammary to LAD and Optimal Medical Treatment in High Risk Patients with Multivessel Coronary Disease Long Term Results. J Cardiol Clin Pract Volume 4(1): 1-2. 